\title{
Erratum to: A hybrid keyword and patent class methodology for selecting relevant sets of patents for a technological field
}

\author{
Christopher L. Benson • Christopher L. Magee
}

Published online: 17 May 2013

(C) Akadémiai Kiadó, Budapest, Hungary 2013

\section{Erratum to: Scientometrics \\ DOI 10.1007/s11192-012-0930-3}

In the original publication of the article, the data in Table 6 "Comparison of the different search methods including the adjusted HKC method" size and relevancy percentage of the cell in row "Electric capacitor" and column "Classification selection" has been published incorrectly as 9,472 (2\%). It should read as 69,277 (7\%). The correct version of Table 6 is provided below.

Table 6 Comparison of the different search methods including the adjusted HKC method

\begin{tabular}{lrrrr}
\hline Field of interest & HKC & HKC modified & Keyword & Classification selection \\
\hline Photovoltaic electricity & $5,101(85 \%)$ & $5,101(85 \%)$ & $1,006(75 \%)$ & $7,233(57 \%)$ \\
Wind turbine & $1,346(94 \%)$ & $2,078(94 \%)$ & $1,843(91 \%)$ & $12,893(26 \%)$ \\
Electric capacitor & $6,173(84 \%)$ & $6,173(84 \%)$ & $11,026(43 \%)$ & $69,277(7 \%)$ \\
Electrochemical battery & $22,115(62 \%)$ & $16,466(83 \%)$ & $1,157(87 \%)$ & $26,111(62 \%)$ \\
Computed tomography & $3,827(91 \%)$ & $7,330(84 \%)$ & $1,289(98 \%)$ & $10,444(69 \%)$ \\
\hline
\end{tabular}

The online version of the original article can be found under doi:10.1007/s11192-012-0930-3.

\section{L. Benson $(\bowtie)$}

Department of Mechanical Engineering, Massachusetts Institute of Technology, 77 Massachusetts Avenue, Cambridge, MA 02139, USA

e-mail: cbenson@mit.edu

\section{L. Magee}

Engineering Systems Division and Department of Mechanical Engineering, Massachusetts Institute of Technology, 77 Massachusetts Avenue, Cambridge, MA 02139, USA e-mail: cmagee@mit.edu 